\title{
(2) OPEN ACCESS \\ Third cranial nerve palsy in an 88-year-old man after SARS-CoV-2 mRNA vaccination: change of injection site and type of vaccine resulted in an uneventful second dose with humoral immune response
}

\author{
Maria Pia Cicalese, ${ }^{1,2}$ Francesca Ferrua (10 1, ${ }^{1,2}$ Federica Barzaghi, ${ }^{1,2}$ Federica Cerri, ${ }^{3}$ \\ Matteo Moro, ${ }^{4}$ Alessandro Aiuti, ${ }^{1,2,5}$ Paolo Silvani ${ }^{6}$
}

'San Raffaele Telethon Institute for Gene Therapy, IRCCS San Raffaele Hospital, Milan, Italy ${ }^{2}$ Pediatric Immunohematology and Bone Marrow Transplantation Unit, IRCCS San Raffaele Hospital, Milan, Italy ${ }^{3}$ Division of Neuroscience and Department of Neurology, IRCCS San Raffaele Hospital, Milan, Italy

${ }^{4}$ Infection Control Committee, IRCCS San Raffaele Hospital, Milan, Italy

${ }^{5}$ Vita-Salute San Raffaele University, Milan, Italy ${ }^{6}$ Department of Anesthesia and Intensive Care, IRCCS San Raffaele Hospital, Milan, Italy

\section{Correspondence to}

Dr Alessandro Aiuti;

aiuti.alessandro@hsr.it

Accepted 26 December 2021

Check for updates

(c) BMJ Publishing Group Limited 2022. Re-use permitted under CC BY-NC. No commercial re-use. See rights and permissions. Published by BMJ.

To cite: Cicalese MP, Ferrua F Barzaghi $F$, et al. BMJ Case Rep 2022;15:e246485. doi:10.1136/bcr-2021 246485

\section{SUMMARY}

Vaccines for SARS-CoV-2 currently authorised by the European Medicine Agency are effective, safe and well tolerated in practice. Awareness of rare potential vaccinerelated adverse effects (AEs) is important to improve their recognition, management and reporting. An 88-year-old man attended the emergency department with incomplete palsy of the right third cranial nerve 3 days after the first administration of Moderna mRNA-1273 SARS-CoV-2 vaccine. Imaging ruled out a vascular accident and a vaccine AE was hypothesised. Two weeks of oral steroids led to the patient's recovery, but without evidence of humoral immune response to vaccine. Thus, full immunisation with a dose of Pfizer mRNA-BNT162b2 SARS-CoV-2 vaccine in a different site was attempted. This was uneventful and followed by a robust antibody response. Empirical change of site and vaccine brand may represent a tailored option to obtain full immune protection in selected patients, after vaccine AEs.

\section{BACKGROUND}

Rapid, large-scale, novel SARS-CoV-2 vaccines have thrown a spotlight on rare adverse reactions, including inflammation-mediated immune reactions. ${ }^{1}$ Among the most frequently reported, post-vaccinal nerve paralyses, in particular facial, raise the suspicion of a central nervous system (CNS) thrombotic event and need a specific and fast differential diagnosis in order to put into place an appropriate treatment. A recent published analysis of nerve paralyses after mRNA SARS-CoV-2 vaccines by the WHO pharmacovigilance database concluded that their incidence is not higher than other vaccines. ${ }^{2}$ Although events of third nerve paralyses have not been published so far, only a few cases post-SARS-CoV-2 vaccine are present in the US Vaccine Adverse Event (AE) Reporting System among the 587 cases reported for diplopia, as searched on 3 August 2021 (Centers for Disease Control and Prevention wonder https://wonder.cdc.gov/vaers. html), similar to other inactivated or live-attenuated vaccines. ${ }^{3}$ In addition to the fact that the mechanism of post-SARS-CoV-2 vaccine on nerve palsies has not yet been elucidated, the conduct necessary to complete the vaccination schedule and immunisation status after such event has not yet been established either.

\section{CASE PRESENTATION}

We report the case of an 88-year-old man, with a medical history of ischaemic heart disease, paroxistic atrial fibrillation on anticoagulant therapy, aortic insufficiency and hypertension. No diabetes was reported.

Three days after the first administration of Moderna mRNA-1273 SARS-CoV-2 vaccine in the right deltoid, he was brought to the emergency department for objective dizziness, diplopia and gait instability. Nasopharyngeal swab real time PCR (Polymerase Chain Reaction) for SARS-CoV-2 resulted negative and no signs of active infection were detected. He appeared alert, cooperative, with the right eye abducted and deviated downwards as a unique neurological sign. Brain CT scan, CT angiography and MRI ruled out a vascular accident. Given the temporal relationship, an incomplete palsy of the right third cranial nerve by SARS $\mathrm{CoV}-2$ vaccine was hypothesised and reported to the Italian Drug Agency Database.

The patient (weight $65 \mathrm{~kg}$ ) received prednisone $25 \mathrm{mg} /$ day $(0.38 \mathrm{mg} / \mathrm{kg} /$ day $)$ for 1 week then gradually tapered off over a period of 2 weeks until suspension. This steroid schedule was at a lower dose than that usually adopted for the treatment of cranial nerve palsies, ${ }^{4}$ but eventually led to a fast recovery of the clinical manifestations in our patient after 5 days of treatment.

The choice to adopt a lower dose of steroids was undertaken in consideration of the age of the patient and in order to try not to blunt the vaccine response. However, serum antibodies against the SARS-CoV-2 receptor-binding domain (RBD), performed by luciferase immunoprecipitation system $(0.24$ arbitrary units (AU)) and by routine assay $(<0.4 \mathrm{U} / \mathrm{mL}),{ }^{5}{ }^{6}$ resulted negative 2 and 3 weeks after vaccination, respectively. On the other hand, T cell proliferative responses to the SARSCoV-2 S protein were detectable (Stimulation Index (SI): 19), along with normal proliferative responses to mitogens (PHA, anti-CD3) as well as to other viral antigens (Cytomegalovirus, Varicella-Zoster virus, Herpes simplex virus). This suggested that, in the presence of a normal $\mathrm{T}$ cell response, the steroid course may have had mainly blunted the humoral responses.

Given the fragility of the subject and his highlevel risk of COVID-19, the treating physician considered a positive benefit-risk ratio in favour of a full immunisation with a second dose of a different vaccine to decrease the risk of an $\mathrm{AE}$ recurrence. 
Empirically, a dose of Pfizer mRNA-BNT162b2 SARS-CoV-2 vaccine in the left quadriceps femoris, contralateral to the first vaccine site and nerve paralysis, was administered, in order to reduce the risk of proximity to a potential inflammatory/immune reaction. In point of fact, the second vaccine administration was uneventful and resulted in a further increase of $\mathrm{T}$ lymphocyte proliferative response specific to the SARS-CoV-2 S peptide (SI: 45). Of note, a robust IgG titre to RBD (272.8 AU) and spike proteins (S2 474.3 AU) was also detected 3 weeks after.

\section{OUTCOME AND FOLLOW-UP}

The patient was followed up with serial clinical evaluations and did not show any signs or symptoms after the second vaccine administration.

\section{DISCUSSION}

Mass vaccination during the pandemic has been initiated prioritising the population at high risk of severe SARS-CoV-2 disease, including the elderly $>80$ years of age. Acute peripheral facial nerve paralysis as an $\mathrm{AE}$ following immunisation is a rare adverse reaction (1 of 10000 to 1 of 1000) described in the product information of SARS-CoV-2 mRNA vaccines. However, the incidence of nerve palsy, including facial, is not reported as being higher than other vaccines, such as the Haemophilus influenzae type B vaccine, the pneumococcal 7-valent conjugate, diphtheria, tetanus, whole-cell pertussis vaccine, as well as measles, mumps and rubella vaccine. ${ }^{378}$ Moreover, a recent study demonstrated that the level of reporting of facial nerve palsies after SARSCoV-2 mRNA vaccination was generally equivalent to those following influenza vaccines prior to the COVID-19 pandemic. $^{8}$

Since the first clinical studies on BNT162b2 and mRNA-1273 SARS-CoV-2 vaccines (US Food and Drug Administration 2021), unilateral facial nerve palsy has been observed ${ }^{389}$ or published in single reports of patients with recurrent ${ }^{1011}$ or de novo postvaccine Bell's palsy. ${ }^{12}$

Aside from the most frequently involved facial nerve, published cases involved abducens nerve palsy 2 days after Pfizer-BioNTech SARS-CoV-2 vaccine ${ }^{13}$ and other disimmune ocular AEs. ${ }^{14}$ Recently, a report of multiple left-sided cranial neuropathies (an incomplete oculomotor palsy without ptosis, partial abducens palsy, hypoesthesia in middle and lower trigeminal nerve distributions, as well as facial nerve palsy-House-Brackmann grade III) has been described in a patient whose symptoms started 6 days after receiving the first dose of the Pfizer-BioNTech SARS$\mathrm{CoV}-2$ vaccination.

No defined mechanism has been identified for cranial nerve palsies following SARS-CoV-2 mRNA vaccination. Post-vaccine nerve palsy could be interpreted as an autoimmune phenomenon, occurring via either mimicry of host molecules by the vaccinal antigen or activation of quiescent autoreactive T cells. ${ }^{9}$ Another hypothesis is that the SARS-CoV-2 vaccines might induce innate immune activation from a combined effect of mRNA and lipids, potentially including interferon production that could transiently break peripheral tolerance. ${ }^{10}$

Pathophysiology behind COVID-19-related cranial nerve palsy includes direct invasion of endothelial cells by SARS$\mathrm{CoV}-2$ and indirect damage through pro-inflammatory attack of infected leucocytes. A viral-like inflammatory reaction to the vaccine, with resulting immune-mediated indirect insult along the nerve and subsequent demyelination or localised nerve blood flow reduction, has also been hypothesised. ${ }^{10} 13$ Moreover, along with a deeper knowledge of the pathophysiology of facial nerve palsy after SARS-CoV-2 vaccination or infection, it will be interesting to understand how they may differ from other manifestations of immune-dysregulation at CNS level, such as Guillain-Barré syndrome or myasthenia gravis.

The massive vaccination programme has highlighted the occurrence of neurological paralyses as potential vaccinal AEs, which sometimes simulated vascular accidents in elderly patients with anamnesis of vasculopathies.

The outcome of SARS-CoV-2 immunisation and the continuation of the immunisation programme in these subjects have not been explored to date in the scientific literature.

This report highlights the need to find alternative strategies to complete the vaccination schedule safely in subjects having experienced AEs to the first dose of the SARS-CoV-2 vaccine. Change of vaccine injection site and/or vaccine type may represent a potential option to be explored further. The change of site can reduce the risk of relapse of nerve palsy, possibly elicited by cytokines and/or inflammatory cells migrating toward the affected tissue. The change of vaccine brand may reduce the risk of immune reactions elicited by various vaccine components, which may mimic nerve membrane molecules.

In conclusion, this report is informative for neurologists and emergency care physicians in the context of global SARS-CoV-2 vaccine campaign, while further analyses are needed to clarify the association of third cranial nerve palsy following SARS-CoV-2 vaccination. Moreover, completing the vaccination schedule to achieve full protection in subjects at risk of severe COVID-19 remains challenging and could be evaluated as a tailored strategy in selected patients.

\section{Learning points}

Nerve paralyses after the SARS-CoV-2 vaccine, in particular facial, raise the suspicion of a central nervous system thrombotic event, in particular in elderly patients with a history of vascular accidents.

- Our case is the first reported case of third cranial nerve palsy occurring after the first administration of Moderna mRNA-1273 SARS-CoV-2 vaccine.

- There are no current data from literature on the conduct necessary to complete the vaccination schedule and immunisation status in subjects having experienced postvaccinal nerve palsy.

- We demonstrated the efficacy and safety of a second dose of Pfizer mRNA-BNT162b2 SARS-CoV-2 vaccination performed in a different site in producing a protective humoral response in an elderly person having experienced a severe vaccine complication and no antibody response. Empirical change of site and vaccine brand may represent a strategy to obtain full immune protection in selected patients, after vaccine adverse events.

- Reports of episodes of post-vaccinal nerve palsy should continue to be published in order to better define the pathophysiology of this adverse event and the association with the SARS-CoV-2 vaccines.

- Temporal association between SARS-CoV-2 vaccine and nerve palsy is not proof of causation and, as cases are reported, further research is needed both to establish causality and mechanism.

Acknowledgements We thank the patient, his family and all the San Raffaele Institute consultants who provided support for the clinical management of the patient. We also thank Vito Lampasona for performing humoral immune response to SARS-CoV-2 proteins in the patient. 
Contributors MPC and AA wrote the manuscript and participated in critical discussions about the patient's management. FF, FB and FC acquired the data. MM participated in critical discussions about the patient's management. PS supervised and coordinated the patient's management. All authors (MPC, FF, FB, FC, MM, AA, PS) contributed to the analysis and interpretation of acquired data, critically reviewed the manuscript and agree with its content.

Funding Supported by Fondazione Telethon, Program Project COVID-19 OSR-UniSR.

Competing interests None declared.

Patient consent for publication Obtained.

Provenance and peer review Not commissioned; externally peer reviewed.

Open access This is an open access article distributed in accordance with the Creative Commons Attribution Non Commercial (CC BY-NC 4.0) license, which permits others to distribute, remix, adapt, build upon this work non-commercially, and license their derivative works on different terms, provided the original work is properly cited and the use is non-commercial. See: http://creativecommons.org/ licenses/by-nc/4.0/.

Case reports provide a valuable learning resource for the scientific community and can indicate areas of interest for future research. They should not be used in isolation to guide treatment choices or public health policy.

\section{ORCID iD}

Francesca Ferrua http://orcid.org/0000-0002-5695-4490

\section{REFERENCES}

1 Angeli F, Spanevello A, Reboldi G, et al. SARS-CoV-2 vaccines: lights and shadows. Eur J Intern Med 2021;88:1-8.

2 Renoud L, Khouri C, Revol B, et al. Association of facial paralysis with mRNA COVID-19 vaccines: a Disproportionality analysis using the world Health organization pharmacovigilance database. JAMA Intern Med 2021;181:1243-5.
3 Woo EJ, Winiecki SK, Ou AC. Motor palsies of cranial nerves (excluding VII) after vaccination: reports to the US vaccine adverse event reporting system. Hum Vaccin Immunother 2014;10:301-5.

4 Fieux M, Franco-Vidal V, Devic P, et al. French Society of ENT (SFORL) guidelines. Management of acute Bell's palsy. Eur Ann Otorhinolaryngol Head Neck Dis 2020;137:483-8

5 Secchi M, Bazzigaluppi E, Brigatti C, et al. COVID-19 survival associates with the immunoglobulin response to the SARS-CoV-2 spike receptor binding domain. J Clin Invest 2020;130:6366-78.

6 McMurry R, Lenehan P, Awasthi S, et al. Real-time analysis of a mass vaccination effort confirms the safety of FDA-authorized mRNA COVID-19 vaccines. Med 2021;2:965-78.

7 Manea MM, Dragoș D, Enache I, et al. Multiple cranial nerve palsies following COVID-19 vaccination-Case report. Acta Neurol Scand 2021. doi:10.1111/ane.13548. [Epub ahead of print: 02 Nov 2021].

8 Sato K, Mano T, Niimi Y, et al. Facial nerve palsy following the administration of COVID-19 mRNA vaccines: analysis of a self-reporting database. Int $J$ Infect Dis 2021;111:310-2

9 Cirillo N. Reported orofacial adverse effects of COVID-19 vaccines: the knowns and the unknowns. J Oral Pathol Med 2021;50:424-7.

10 Ozonoff A, Nanishi E, Levy O. Bell's palsy and SARS-CoV-2 vaccines. Lancet Infect Dis 2021;21:450-2.

11 Repajic M, Lai XL, Xu P. Bell's palsy after second dose of Pfizer COVID-19 vaccination in a patient with history of recurrent Bell's palsy. Brain Behav Immun Health 2021;13.

12 Burrows A, Bartholomew T, Rudd J, et al. Sequential contralateral facial nerve palsies following COVID-19 vaccination first and second doses. BMJ Case Rep 2021;14:e243829.

13 Reyes-Capo DP, Stevens SM, Cavuoto KM. Acute abducens nerve palsy following COVID-19 vaccination. J Aapos 2021;25:302-3.

$14 \mathrm{Ng} \mathrm{XL}$, Betzler BK, Testi I, et al. Ocular adverse events after COVID-19 vaccination. Ocul Immunol Inflamm 2021;5:1-9.

Copyright 2022 BMJ Publishing Group. All rights reserved. For permission to reuse any of this content visit

https://www.bmj.com/company/products-services/rights-and-licensing/permissions/

BMJ Case Report Fellows may re-use this article for personal use and teaching without any further permission.

Become a Fellow of BMJ Case Reports today and you can:

- Submit as many cases as you like

- Enjoy fast sympathetic peer review and rapid publication of accepted articles

- Access all the published articles

Re-use any of the published material for personal use and teaching without further permission

\section{Customer Service}

If you have any further queries about your subscription, please contact our customer services team on +44 (0) 2071111105 or via email at support@bmj.com.

Visit casereports.bmj.com for more articles like this and to become a Fellow 